\title{
Los corticoides fueron ineficaces para el tratamiento de la bronquiolitis moderada y severa
}

Steroids were not useful for the treatment of moderate and severe bronchiolitis

Cornelli H y col. N Engl J Med 2007, 357:331-9.

\section{Objetivo}

Evaluar si el tratamiento con dexametasona disminuye la tasa de internaciones y mejora los índices respiratorios de los pacientes con bronquiolitis.

\section{Diseño}

Ensayo clínico multi-céntrico, aleatorizado, controlado y dobleciego.

\section{Lugar}

20 Centrales de Emergencia de Estados Unidos.

\section{Pacientes}

Participaron 600 lactantes de dos a 12 meses de vida durante su primer episodio de bronquiolitis de moderada a severa gravedad de acuerdo al puntaje RDAI, que toma en cuenta signos clínicos como la magnitud de las sibilancias y de la retracción del tórax.

\section{Intervención}

600 lactantes fueron aleatorizados a recibir por vía oral una única dosis de $1 \mathrm{mg} / \mathrm{kg}$ de dexametasona o placebo. Por razones éticas, prácticas y científicas, los equipos médicos tratantes indicaron los métodos diagnósticos y/o terapéuticos que consideraron apropiados para cada caso, habiendo recibido tratamiento broncodilatador durante su estadía en la central de emergencias el $77 \%$ de los asignados a dexametasona y el $80 \%$ de los asignados a placebo.

\section{Medición de resultados principales}

El resultado primario evaluado fue la indicación de internación luego de cuatro horas de observación en la central de emergencias y secundariamente, los cambios en los parámetros respiratorios mediante el puntaje de evaluación del cambios respiratorios (en inglés RACS y basado en el descripto previamente); ambos con análisis por intención de tratar*.

\section{Resultados principales}

No hubo diferencias clínicamente relevantes entre ambos grupos en los resultados evaluados. Ver tabla 1.

Tabla 1: comparación de los resultados entre lo pacientes con un primer episodio de bronquilitis moderada o severa asignados a una única dosis oral de dexametasona o de placebo sumados a los cuidados usuales.

\begin{tabular}{|c|c|c|c|c|}
\hline \multicolumn{2}{|c|}{ Resultado por grupo } & $\begin{array}{c}\text { Dexametasona } \\
(n=305)\end{array}$ & $\begin{array}{l}\text { Placebo } \\
(n=295)\end{array}$ & $\begin{array}{c}\text { RRR } \\
\text { (IC95\%) }\end{array}$ \\
\hline \multicolumn{2}{|c|}{ Internación hospitalaria } & $39,7 \%$ & $41 \%$ & $-1,3 \%(-9,2$ a 6,5$)$ \\
\hline \multirow[t]{2}{*}{ Puntajes } & $\begin{array}{l}\text { De cambio } \\
\text { respiratorio }\end{array}$ & $-5,3+/-4,7$ & $-4,8+/-4,6$ & $-0,5(-1,3$ a 0,3$)$ \\
\hline & De severidad & $-4,4+/-3,1$ & $-3,9+/-3,2$ & $-0,5(-1,0$ a $\quad-0,1)$ \\
\hline
\end{tabular}

RRR: reducción del riesgo relativo.

\section{Conclusiones}

El estudio demostró que no hay una reducción significativa en la tasa de internación luego de una única dosis oral de $1 \mathrm{mg} / \mathrm{kg}$ de dexametasona en lactantes de 2 a 12 meses con su primer episodio de bronquiolitis de gravedad moderada a severa.

Palabras claves: bronquiolitis, dexametasona, internación, cambio respiratorio. Key words: bronchiolitis, dexamethasone, admision, respiratory change. Fuente de financiamiento y/o conflictos de interés: Maternal and Chile Health Research program, the Emergency Medical Services for Children program of the Maternal And Child Health Bureau, Health Resources and Services Administration, EE.UU. El Dr. Zorc recibió ayuda de Sepracor y el Dr Holubkow recibió un subsidio de de St. Jude Medical y GlaxoSmithKline.

\section{Comentario}

La bronquiolitis es la infección de la vía aérea baja más común en los lactantes y la causa más frecuente de internación a esa edad $^{1,2}$; existiendo documentación de una considerable variabilidad en nuestro medio en cuanto al manejo de esta enfermedad $^{2}$. La indicación de corticoides sistémicos con el objetivo de disminuir la inflamación a nivel de vía aérea distal es una práctica muy difundida. Sin embargo, los estudios que la habían evaluado anteriormente fueron heterogéneos y de pequeño tamaño, por lo que Cornelli y col. decidieron realizar el ensayo (que hemos resumido) con un $80 \%$ de poder* para determinar la eficacia de esta estrategia ${ }^{3}$. Si bien los resultados del puntaje con el que se evaluó el patrón respiratorio mostraron diferencias estadísticamente significativas a favor del grupo que había sido asignado a dexametasona, estas reducciones (de 0,5 puntos) no serían clínicamente relevantes. Es importante resaltar que durante la observación se permitió libremente la realización de otras medidas terapéuticas como oxigenoterapia o el uso de broncodilatadores. Si bien esto podría interpretarse como una "co-intervención", vale aclarar que ambos grupos recibieron igual intensidad de dicha intervención (por ejemplo broncodilatadores) lo que aleja la proba- bilidad de que ésta haya actuado como un factor de confusión de los resultados. Si bien, este tipo de diseño otorga menor validez interna* a este estudio, mejora su validez externa*, volviendo a sus resultados más generalizables en nuestra práctica diaria. Entre las limitaciones del trabajo que comentamos, mencionamos que faltó evaluar el efecto del tratamiento ambulatorio con corticoides luego del alta de la central de emergencias, práctica ampliamente difundida ya que muchos profesionales indican cuatro o cinco días más de una dosis diaria similar a la empleada en este trabajo; y que los autores no reportaron algunas características basales de la población estudiada que podrían influir en la toma de decisiones en nuestro medio como las socioeconómicas, el estado de nutrición, la accesibilidad al sistema de salud, etc.

\section{Conclusiones del comentador}

En una muestra de lactantes de EEUU, una monodosis de corticoides sistémicos no mostró eficacia para reducir la tasa de internaciones en pacientes con bronquiolitis moderada o severa y no influiría en la historia natural de la enfermedad.

Ignacio Vicente Lago [ Servicio de Medicina Familiar del Hospital Italiano de Buenos Aires. ignacio.vicente@ hospitalitaliano.org.ar ]

Lago I. Los corticoides fueron ineficaces para el tratamiento de la bronquiolitis moderada y severa. Evid. actual. práct. ambul; 11(6): 173. Nov-Dic 2008. Comentado de: Cornelli $\mathbf{H}$ y col. A Multicenter, Randomized, Controlled Trial of Dexamethasone for bronchiolitis. N Engl J Med 2007, 357:3319. PMID: 17652648. Disponible en: http://content.nejm.org/cgi/reprint/357/4/331.pdf

\section{Referencia}

1. Mouesca J. Infecciones de la vía aérea baja en los niños. Capítulo 66. En: "Medicina Familiar y Practica Ambulatoria". Editores Rubinstein A y Terrasa S. Editorial Médica Panamericana, Enero de 2006. pp 551-563.

2. Bernstein R y col. Variability in the management of bronchiolitis in the public first level of attention in Argentina. Arch. Argent. Pediatr., May/June 2008, vol.106, no.3, p.205211. ISSN 0325-0075.

3. Rockville, MD. Management of bronchiolitis in infants and children. Agency for Healthcare Research and Quality, January 2003. (AHRQ publication no. 03-E014.) 